\title{
Role of Thrombophilia in Neonatal Thrombosis as A Risk Factor Atef Mahammad Khalil ${ }^{1}$, Ehab Abd Elmenem Al banna', Zahrah Saleh Huwas', Doaa Metwally Abd Almonem²
}

Department of ${ }^{1}$ Pediatrics and ${ }^{2}$ Clinical Pathology, Faculty of Medicine - Zagazig University, Egypt

*Corresponding author: Zahrah Saleh Huwas, Mobile: (+20) 01091876368, E-mail: dr.zohrarahawass@ gmail.com

\begin{abstract}
Background: Thrombosis in neonates is rare and usually occurs as a secondary complication of underlying disease, e.g. sepsis or congenital heart disease, or exogenous triggers such as intravascular catheters.

Objective: This study aimed to identify the incidence rates, risk factors and outcomes of neonates with thrombosis admitted to NICU.

Patients and methods: This study was a cohort study conducted in Multiple Neonatal ICU in Sharkia Hospitals in the period from April 2020 to September 2020. The study included 24 neonates, with thrombotic disorders admitted to NICU. The included patients were subjected to careful history taking, clinical and neurological examination and laboratory investigations.

Results: Three patients (12.5\%) had wild mutation of factor V gene mutation while $20.8 \%$ had wild mutation of prothrombin gene mutation. All patients had MTHFR C6771 mutation. Out of them $16.7 \%$ and $83.3 \%$ had homozygous and heterozygous types .There was statistically significant relation between presence of factor V G1691 gene mutation and d-dimer, which is significantly higher in wild type mutation.

Conclusion: The most important risk factor for thrombo-embolic events in neonates is placement of central catheters and some perinatal prothrombotic conditions.
\end{abstract}

Keywords: Thrombophilia, Neonatal, Thrombosis, Venous thromboembolism (VTE).

\section{INTRODUCTION}

Thrombosis in neonates is rare and usually occurs as a secondary complication of underlying disease (sepsis, congenital heart disease, or exogenous triggers such as intravascular catheters $)^{(\mathbf{1})}$.

The epidemiology of pediatric venous thromboembolism (VTE) shows a bimodal distribution with a peak in the neonatal period and a second peak in the adolescence. There is a sharp increase of the incidence of VTE from 1990 to 2007 with 53 to 58 cases per 10,000 hospital admissions and 24 per 10,000 NICU admissions ${ }^{(2)}$.

Neonatal thrombo-embolic events are a serious problem. Long-term sequelae or death may be the result. In childhood, the highest incidence of thrombo-embolic events is during the first year of life. The manifestations of neonatal TE are arterial ischemic stroke (AIS), cerebral venous sinus thrombosis (CVST), deep vein thrombosis (DVT), renal vein thrombosis (RVT), portal vein thrombosis (PVT), systemic arterial TE (ATE), intracardiac thrombus, and purpura fulminans $(\mathrm{PF})^{(\mathbf{3}, \mathbf{4})}$.

Compared to childhood, developmental hemostasis in the neonatal period contains lower levels of anticoagulation proteins such as protein $\mathrm{C}$ (PC), protein $\mathrm{S}$ (PS), antithrombin (AT) and heparin cofactor II, increased procoagulants such as factor VIII and von Willebrand factor (vWF), and reduced fibrinolytic capacity such as decreased plasminogen and increased plasminogen activator inhibitor-1. As a result, the risk of TE is higher in neonates than in the children ${ }^{(4)}$.

The term 'thrombophilia' is used for inherited or acquired coagulation disorders that have been associated with an increased risk for thrombosis. These include activated protein-C resistance, which can be based on the inherited factor-V Leiden mutation, deficiencies of protein $\mathrm{C}, \mathrm{S}$ or antithrombin, the prothrombin G20210A (factor II) mutation or hyperhomocysteinemia, which is nutritional derived or based on the 5,10-methylenetetrahydrofolate reductase gene (MTHFR) mutation ${ }^{(5)}$.

Changes in the levels of procoagulants, anticoagulants, and fibrinolysis factors, or the diameter of small vessels put neonates at an increased risk for thrombosis, especially in the presence of other hemostatic challenges, such as indwelling catheters ${ }^{(\boldsymbol{6})}$.

Central catheterization (venous or arterial) is the primary iatrogenic risk factor for neonatal thrombosis. Additional risk factors include elevated hematocrit, perinatal asphyxia, maternal diabetes, maternal preeclampsia, polycythemia, sepsis, necrotizing enterocolitis, small for gestational age, dehydration, underlying disease (e.g. metabolic disorder, congenital heart disease [CHD], and congenital nephrotic syndrome), disseminated intravascular coagulation, respiratory distress syndrome (RDS), systemic steroid therapy, major surgery, and prothrombotic disorders ${ }^{(4)}$.

This study aimed to identifying the incidence rates, risk factors and outcomes of neonates with thrombosis admitted to NICU.

\section{PATIENTS AND METHODS}

The study included 24 neonates, as the rate of neonates with thrombotic disorders admitted to NICU is $1 /$ week and $4 /$ month so total number admitted at the period of sex months was 24 neonates and all of them were taken as comprehensive sample from April 2020 to September 2020. 
Inclusion criteria: Neonates (birth to 28 days) with a symptomatic or asymptomatic venous and arterial systemic thromboembolism confirmed by an imaging technique.

Exclusion criteria: Thromboembolic events diagnosed after neonatal age, and sickle cell anemia.

All patients were subjected to detailed medical history with special emphasis on demographic data (sex, mother age/ race/ ethnicity, maternal antenatal medical condition, type of delivery, gestational age by Ballard, birth weight, neonatal medical condition, delayed crying, hypoxia and convulsion). Daily full neonatal clinical examination. Laboratory investigations included CBC, quantitative assessment of the level of C-reactive protein (CRP), blood culture and sensitivity, lumber puncture; CSF analysis, urine analysis, blood urea and electrolytes, blood sugar, urea, creatinine, $\mathrm{Na}$, $\mathrm{K}, \mathrm{Ca}, \mathrm{CL}, \mathrm{Mg}$, liver function test [SGOT, SGPT, Bilirubin (total, direct, indirect)], arterial blood gases [ABG], prothrombin time [PT], partial thromboplastin time [PTT] and D-dimer, INR. Moreover, Genetic CVD risk factor (THROMBOPHILIA GENE), Factor V gene mutation [factor V Leiden G1691], prothrombin gene mutation [G20210A] and MTHFR C677T mutation were estimated. Assay for the identification of factor $\mathrm{V}$ $(\mathrm{FV})$, prothrombin $(\mathrm{PTH})$ and MTHFR gene mutations based on polymerase chain reaction (PCR) and reversehybridization.

\section{Imaging:}

Thrombosis in the major vessels was diagnosed using Doppler ultrasonography (USG). Intracardiac thrombosis was diagnosed using echocardiography and thrombi in the central nervous system (CNS) was diagnosed using brain magnetic resonance imaging (MRI), MRI and/or computed tomography angiography.

\section{Ethical Clearance:}

The study was approved by the Institutional Ethics Committees of Zagazig University. Written informed consent was taken from the parents of enrolled neonate. (zu_IRB\#6084/10-5-2020).

The research was carried out in compliance with the World Medical Association's Code of Ethics (Helsinki Declaration) of human-related studies.

\section{Statistical Analysis}

Data collected throughout history, basic clinical examination, laboratory investigations and outcome measures were coded, entered and analyzed using Microsoft Excel software. Data were then imported into Statistical Package for the Social Sciences (SPSS version 20.0) software for analysis. According to the type of data, qualitative were represented as number and percentage, while quantitative continues were represented as mean $\pm \mathrm{SD}$.

The following tests were used to test differences for significance: difference and association of qualitative variable by Chi square test $\left(\mathrm{X}^{2}\right)$ and differences between quantitative independent groups by $t$ test. P value was set at $\leq 0.05$ for significant result \& $<0.001$ for high significant result.

\section{RESULTS}

Table (1): Distribution of the studied patients according to demographic data

\begin{tabular}{||c|c|c|}
\hline & $\mathbf{N = 2 4}$ & $\mathbf{\%}$ \\
\hline \hline Gender: & & \\
Male & 9 & 37.5 \\
Female & 15 & 62.5 \\
\hline Age (days): & & \\
Median & 15 & \\
Range & $1-30$ & \\
\hline Birth weight (gm) & & \\
ELBW (<1000gm) & & \\
VLBW (1000- & 1 & $4.4 \%$ \\
<1500gm) & 3 & $12.6 \%$ \\
LBW (1500 - <2500 & 9 & $37.3 \%$ \\
gm) & 11 & $45.7 \%$ \\
$\geq 2500$ gm & & \\
\hline Mode of delivery: & 10 & 41.7 \\
NVD & 14 & 58.3 \\
CS & & \\
\hline \multicolumn{2}{|l}{} \\
\hline
\end{tabular}

Females represented $62.5 \%$ of the studied patients. Their ages ranged from 1 to 30 days with median 15 days. About $58 \%$ of patients were delivered by CS mode as shown in table (1). 
Table (2): Distribution of cases according to data at the Neonatal Intensive Care Unit

\begin{tabular}{|c|c|c|c|c|c|}
\hline Socio-demographic data & No & $\%$ & $\chi^{2}$ & p-value & Odds (CI 95\%) \\
\hline $\begin{array}{l}\text { Gestational age } \\
<37 \text { weeks } \\
\geq 37 \text { weeks }\end{array}$ & $\begin{array}{l}11 \\
13\end{array}$ & $\begin{array}{l}45.8 \\
54.2\end{array}$ & 0.04 & 0.8 & $\begin{array}{c}0.9 \\
(0.5 \%-1.8 \%)\end{array}$ \\
\hline $\begin{array}{l}\text { Neonatal age at admission } \\
<3 \text { days } \\
\geq 3 \text { days }\end{array}$ & $\begin{array}{l}24 \\
0.0\end{array}$ & $\begin{array}{l}100 \\
0.0\end{array}$ & 23.1 & $0.001 * *$ & $\begin{array}{c}0.6 \\
(0.5 \%-0.7 \%)\end{array}$ \\
\hline $\begin{array}{l}\text { Sex } \\
\text { Male } \\
\text { Female }\end{array}$ & $\begin{array}{c}9 \\
15\end{array}$ & $\begin{array}{l}37.5 \\
62.5\end{array}$ & 0.2 & 0.7 & $\begin{array}{c}0.9 \\
(0.5 \%-1.6 \%)\end{array}$ \\
\hline Sepsis & 24 & $100 \%$ & 23.1 & $0.001 * *$ & $\begin{array}{c}0.6 \\
(0.5 \%-0.7 \%)\end{array}$ \\
\hline $\begin{array}{l}\text { Maternal age (years) } \\
<30 \\
>30\end{array}$ & $\begin{array}{l}11 \\
13\end{array}$ & $\begin{array}{l}45.8 \\
54.2\end{array}$ & FET & 0.6 & $\begin{array}{c}1.3 \\
(0.4 \%-4.9 \%)\end{array}$ \\
\hline $\begin{array}{l}\text { Apgar Score } \\
<7 \\
\geq 7\end{array}$ & $\begin{array}{c}9 \\
15\end{array}$ & $\begin{array}{l}37.5 \\
62.5\end{array}$ & 0.2 & 0.7 & $\begin{array}{c}0.9 \\
(0.5 \%-1.6 \%)\end{array}$ \\
\hline $\begin{array}{l}\text { Lower limb oedema } \\
\text { No } \\
\text { Yes }\end{array}$ & $\begin{array}{l}14 \\
10\end{array}$ & $\begin{array}{l}58.4 \\
41.6\end{array}$ & 3.7 & 0.06 & $\begin{array}{c}0.6 \\
(0.3 \%-1.1 \%)\end{array}$ \\
\hline $\begin{array}{l}\text { Hematocrit }(\%) \\
<35 \\
\geq 35\end{array}$ & $\begin{array}{l}11 \\
13\end{array}$ & $\begin{array}{l}45.8 \\
54.2\end{array}$ & 0.04 & 0.8 & $\begin{array}{c}0.9 \\
(0.5 \%-1.8 \%)\end{array}$ \\
\hline
\end{tabular}

M.W= Mann-Witenny, Statistically significant difference $(\mathrm{P} \leq 0.05)$, statistically highly significant difference $(\mathrm{P} \leq 0.001)$.

Table (2) showed that there was statistically highly significant increase in neonatal thrombosis and decreasing age in neonate with sepsis at admission.

Table (3): Distribution of the studied patients according to present history

\begin{tabular}{|l|c|c|}
\hline & $\mathbf{N = 2 4}$ & \% \\
\hline \hline Congenital anomalies: & 14 & 54.2 \\
No & 10 & 45.8 \\
Yes & 19 & \\
\hline GI surgery: & 5 & 79.2 \\
No & 24 & 20.8 \\
Yes & & 100 \\
\hline Sepsis & 14 & 58.3 \\
UVC: & 10 & 41.7 \\
No & 15 & \\
Yes & 9 & 62.5 \\
\hline SGA: & & 37.5 \\
No & 24 & 100 \\
Yes & & \\
\hline CVL & 12 & 50 \\
Negative & 12 & 50 \\
\hline Pneumonia: & & \\
No & & \\
Yes & & \\
\hline
\end{tabular}

Congenital anomalies prevailed in $45.8 \%$ of patients. About $21 \%$ had history of GI surgery. All of them had sepsis. Pneumonia occurred in 50\%, of patients (Table 3). 
Table (4): Distribution of the studied patients according to thrombophilia genes

\begin{tabular}{|l|c|c|}
\hline & $\mathbf{N}=\mathbf{2 4}$ & $\mathbf{\%}$ \\
\hline \hline Factor V gene mutation G1691: & & \\
Normal \\
Wild type & 21 & 87.5 \\
\hline Prothrombin gene mutation G20210A: & 3 & 12.5 \\
Normal & & \\
Wild type & 19 & 79.2 \\
\hline MTHFR C6771 mutation: & 5 & 20.8 \\
Homozygous & & \\
Heterozygous & 4 & 16.7 \\
\hline
\end{tabular}

Table (4) showed that three patients (12.5\%) had wild mutation of factor $\mathrm{V}$ gene mutation, while $20.8 \%$ had wild mutation of prothrombin gene mutation. All patients had MTHFR C6771 mutation. Out of them, 16.7\% and 83.3\% had homozygous and heterozygous types respectively.

Table (5): Relation between gene mutation and D -dimer among the studied patients

\begin{tabular}{|l|c|c|c||}
\hline \multicolumn{1}{|c|}{ Gene mutation } & Mean \pm SD & t & p \\
\hline \hline Factor V G1691: & & & \\
Normal & $4.61 \pm 1.47$ & -3.951 & $0.001^{* *}$ \\
Wild type & $6.07 \pm 0.06$ & & \\
\hline Prothrombin G20210A: & & & $0.001^{* *}$ \\
Normal & $5.58 \pm 0.78$ & 7.582 & \\
Wild type & $2.77 \pm 0.46$ & & \\
\hline MTHFR C6771 mutation: & & & 0.21 \\
Homozygous & $4.4 \pm 0.08$ & & \\
Heterozygous & $4.95 \pm 1.62$ & -1.313 & \\
\hline
\end{tabular}

${ }^{* *} \mathrm{p} \leq 0.001$ is statistically highly significant $\mathrm{t}$ Independent sample $\mathrm{t}$ test

Table (5) showed that there was statistically significant increase of D dimer and presence of factor V G1691 gene mutation in neonates with thrombosis. There was statistically significant decrease in D dimer and presence of prothrombin G20210A gene mutation in neonates with thrombosis. There was statistically non-significant relation between presence of MTHFR C6771 gene mutation and d- dimer, which is non-significantly lower in homozygous mutation. 
Table (6): Comparison between risk factors AND neonatal thrombosis

\begin{tabular}{|c|c|c|c|c|c|}
\hline \multirow{2}{*}{ Perinatal History } & \multicolumn{2}{|c|}{ Neonatal thrombosis } & \multirow{2}{*}{$\chi^{2}$} & \multirow{2}{*}{ p-value } & \multirow{2}{*}{$\begin{array}{c}\text { Odds } \\
\text { (CI 95\%) }\end{array}$} \\
\hline & No (24) & $\%$ & & & \\
\hline $\begin{array}{c}\text { Congenital anomalies } \\
\text { No } \\
\text { Yes }\end{array}$ & $\begin{array}{l}14 \\
10\end{array}$ & $\begin{array}{l}58.3 \\
41.6\end{array}$ & 6.8 & 0.008* & $\begin{array}{c}2.6 \\
(1.2 \%-5.4 \%)\end{array}$ \\
\hline $\begin{array}{r}\text { Sepsis } \\
\text { NO } \\
\text { Yes }\end{array}$ & $\begin{array}{c}0 \\
24\end{array}$ & $\begin{array}{c}0 \\
100\end{array}$ & 4.6 & $0.001 *$ & $\begin{array}{c}0.4 \\
(0.2 \%-0.9 \%)\end{array}$ \\
\hline $\begin{array}{l}\text { Liver functions } \\
\text { Elevated bilirubin } \\
\text { Elevated SGOT } \\
\text { Elevated SGPT } \\
\end{array}$ & $\begin{array}{l}20 \\
14 \\
10 \\
\end{array}$ & $\begin{array}{l}83.1 \\
58.3 \\
41.6 \\
\end{array}$ & 10.1 & $0.01 *$ & N.A \\
\hline $\begin{array}{ll}\text { UVC } & \\
& \text { No } \\
& \text { Yes }\end{array}$ & $\begin{array}{c}9 \\
15\end{array}$ & $\begin{array}{l}37.5 \\
62.5\end{array}$ & 33.2 & $0.001 * *$ & $\begin{array}{c}6.3 \\
(3.2 \%-12.1 \%)\end{array}$ \\
\hline $\begin{array}{l}\text { TPN } \\
\text { No } \\
\text { yes }\end{array}$ & $\begin{array}{l}11 \\
13\end{array}$ & $\begin{array}{l}85.9 \\
14.1\end{array}$ & 9.8 & $0.001 * *$ & $\begin{array}{c}4.3 \\
(1.6 \%-11.5 \%)\end{array}$ \\
\hline $\begin{array}{ll}\text { PPN } & \\
& \text { No } \\
& \text { Yes }\end{array}$ & $\begin{array}{c}9 \\
15\end{array}$ & $\begin{array}{l}37.5 \\
62.5\end{array}$ & 2.1 & 0.14 & $\begin{array}{c}0.6 \\
(0.3 \%-1.6 \%)\end{array}$ \\
\hline $\begin{array}{ll}\text { MV } & \\
& \text { No } \\
\text { yes }\end{array}$ & $\begin{array}{l}10 \\
14\end{array}$ & $\begin{array}{l}41.6 \\
58.3\end{array}$ & 9.8 & $0.001 * *$ & $\begin{array}{c}4.3 \\
(1.6 \%-11.5 \%)\end{array}$ \\
\hline $\begin{array}{l}\text { CPAP } \\
\text { No } \\
\text { Yes }\end{array}$ & $\begin{array}{c}4 \\
20\end{array}$ & $\begin{array}{l}16.6 \\
83.3\end{array}$ & 2.1 & $0.001 * *$ & $\begin{array}{c}0.6 \\
(0.3 \%-1.6 \%)\end{array}$ \\
\hline $\begin{array}{c}\text { Hematocrit }>35 \\
\text { No } \\
\text { yes }\end{array}$ & $\begin{array}{l}11 \\
13\end{array}$ & $\begin{array}{l}45.8 \\
54.1\end{array}$ & 9.8 & $0.001 * *$ & $\begin{array}{c}4.3 \\
(1.6 \%-11.5 \%)\end{array}$ \\
\hline $\begin{array}{c}\text { Lower limb edema } \\
\text { No } \\
\text { Yes }\end{array}$ & $\begin{array}{l}14 \\
10\end{array}$ & $\begin{array}{l}58.3 \\
41.6\end{array}$ & 2.1 & 0.14 & $\begin{array}{c}0.6 \\
(0.3 \%-1.6 \%)\end{array}$ \\
\hline $\begin{array}{ll}\text { CVL } & \\
& \text { No } \\
& \text { Yes } \\
\end{array}$ & $\begin{array}{c}24 \\
0 \\
\end{array}$ & $\begin{array}{c}100 \\
0\end{array}$ & 2.1 & 0.14 & $\begin{array}{c}0.6 \\
(0.3 \%-1.6 \%) \\
\end{array}$ \\
\hline
\end{tabular}

* Statistically significant difference $(P \leq 0.05) * *$ Statistically highly significant difference $(P \leq 0.001)$

Table (6) showed that there were statistically highly significant risk factors of thrombosis in neonates with sepsis, UVC, hematocrit > 35, CPAP, MV, TPN and congenital anomalies. 
Table (7): Incidence of neonatal thrombosis at the neonatal intensive care units at Sharkia at the period of study

\begin{tabular}{|l|l|}
\hline $\begin{array}{l}\text { Incidence of neonatal thrombosis at the } \\
\text { neonatal intensive care units }\end{array}$ & $34 \%$ \\
\hline
\end{tabular}
was $34 \%$.

Incidence of neonatal thrombosis in our study

\section{DISCUSSION}

The results of this study showed that the mean of birth weight of studied neonates was $2300 \pm 900 \mathrm{gm}$. $45.7 \%$ of admitted neonates were $\geq 2500$ gm, $37.3 \%$ were LBW, $12.6 \%$ were VLBW and $4.4 \%$ were ELBW. This is similar to Rakholia et al. ${ }^{(7)}$. While another study showed that high frequency of LBW babies (54\%) and low frequency VLBW babies $(6 \%)^{(8)}$.

The results of this study showed that the mean of gestational age of the studied neonates was $35.3 \pm 2.7$ weeks and preterm were $55.9 \%$ and terms were $44.1 \%$ with preterm to term ratio equal 1.3:1. This matches with another study conducted by Ferraresi \& Arrais (9). On the other hand, another studies reported high frequency of term neonates' admission with thrombosis (10).

Increased preterm admission rate in our NICU because our hospital is a tertiary hospital that receives high-risk pregnant women and referral for critically ill preterm neonates and the variation in term and preterm admissions in other studies might be explained by levels of neonatal care and quality of hospital care in studies localities.

The results of this study showed that the mean of neonatal age at admission to NICU was $3.01 \pm 2.0$ days and this matches with Farah $\boldsymbol{e t}$ al. ${ }^{(11)}$.

In this study, congenital anomalies prevailed in $45.8 \%$ of patients. About $21 \%$ had history of GI surgery. All of them had sepsis. Pneumonia, dehydration and jaundice occurred in $20.8 \%, 50 \%$ and $8.3 \%$ of patients respectively.

Increased surgical problems admissions in our study explained by availability of neonatal surgical unit in our hospital that considered as a referral unit for neonatal surgical problems. A study conducted in a tertiary NICU from June 2001 to May 2011 (10 yrs) in a medical college teaching hospital in South India, showed matched results that surgical newborns were $4.6 \%$ of neonatal admissions and GIT anomalies are the most important causes necessitating surgical interventions in the immediate newborn period ${ }^{(\mathbf{1 2})}$. As well as Ugwu and Okoro ${ }^{(\mathbf{1 3})}$ reported that the incidence of neonatal surgical problems was $6.2 \%$ and congenital anomalies were more than $80 \%$ of all neonatal surgical diseases and the most frequent surgical problems in the neonates involve GIT.

Surveillance conducted by the ministry of health, Egypt (2010-2014) to determine prevalence of neonatal sepsis in Egyptian governorates NICUs showed that highest prevalence was in North Sinai $12.83 \%$ and lowest prevalence was in Dakahleya $(2.56 \%)^{(14)}$. High
Prevalence of neonatal infections as our study was reported in Ethiopia (77.9\%) and Iran $(51.8 \%){ }^{(15)}$. Cailes et al. ${ }^{(16)}$ reported low prevalence of neonatal infections in UK as 6.1/1000 live births and 48.8/1000 neonatal admissions. Differences in prevalence of infections in NICUs among the studies may be partially explained by used methodology, particularly in relation to the definitions of infection and populations and locality, availability of resources in NICUs and infection control measures.

This study included patients with microbiologically established infections and with clinical evidence of infection. Also, it is prominent that this study was conducted in a University Hospital, which serves entirely the public health sector and is the reference center for high risk pregnancies in the whole governorate and complicated critically ill neonates. The explanation of increased prevalence of neonatal infections in different manipulation may be due to increased possibility of prolonged hospital stay, increased healthcare-providers contact to admitted neonates and contaminated environment and devices circuits. In the current study three patients $(12.5 \%)$ had wild mutation of factor $\mathrm{V}$ gene mutation while $20.8 \%$ had wild mutation of prothrombin gene mutation. All patients had MTHFR C6771 mutation. Out of them, $16.7 \%$ and $83.3 \%$ had homozygous and heterozygous types respectively.

Heller $\boldsymbol{e t}$ al. ${ }^{\left({ }^{(17)}\right.}$ described neonatal thrombosis as one of the pathologic conditions associated with abdominal venous thrombosis in neonates and infants in a multicentered study that involved 65 infants. In the study conducted by Martin-Ancel $\boldsymbol{e t}$ al. ${ }^{\left({ }^{(18)}\right.}$ thrombosis occurred in $26 \%$ of cases, whereas hematemesis occurred in $35 \%$ of the hypoxic-ischemic neonates. Gastrointestinal complications in the form of necrotizing enterocolitis and rectal bleeding occurred in $29 \%$ of cases.

In this study, there was statistically significant relation between presence of factor V G1691 gene mutation and d- dimer, which is significantly higher in wild type mutation. There was statistically significant relation between presence of prothrombin G20210A gene mutation and d- dimer, which was significantly lower in wild type mutation. There was statistically nonsignificant relation between presence of MTHFR C6771 gene mutation and d-dimer, which was nonsignificantly lower in homozygous mutation, which could be the cause of the increased thrombotic tendency in patients suffering from this insult. In the present study, the frequency of the three mutations is similar to that reported for the Italian general population. A mutation in factor $\mathrm{V}$ gene is independent risk factor for venous thrombosis. This is in contrast to other study that showed high risk of cerebral vein thrombosis in carriers of a prothrombin-gene mutation and in users of oral contraceptives ${ }^{(19)}$. A mutation in the factor $\mathrm{V}$ gene is associated with venous, but not arterial, thrombosis in lupus anticoagulant-positive patients. Therefore, its evaluation is useful for the identification of cases at 
particularly high risk of venous thrombosis. Conversely, the investigation of other two common polymorphisms, the $\mathrm{G} 20210 \rightarrow$ A mutation in the factor II gene and the C677 $\rightarrow$ T mutation in the MTHFR gene, does not seem to help to define the risk of thrombosis of lupus anticoagulant-positive patients ${ }^{(20)}$.

Thus morbidity and mortality in individuals with thrombophilia are primarily the result of VTE and PE. The risk for thrombosis may be significantly increased in individuals with a combination of two or more risk factors for thrombosis. Any multiplicity of risk factors, whether acquired or hereditary, elevates the risk for thrombosis.

Incidence of neonatal thrombosis in our study was $34 \%$. A study conducted in tertiary NICU from June 2001 to May 2011 (10 years) in Medical College Teaching Hospital in South India showed matched results that thrombophilic newborn were $4.6 \%$ of neonatal admissions ${ }^{(12)}$. As well Ugwu and Okoro ${ }^{(13)}$ reported that the incidence of neonatal thrombosis was $6.2 \%$. Incidence of thrombosis in different Egyptian NICUs were $20 \%, 21.4 \%, 28 \%$ and $30 \%$ in Al-Azhar University, Mansoura University, Ain Shams University and South Sina State Hospital respectively $(\mathbf{1 4}, \mathbf{2 1}, \mathbf{2 2})$. High incidence of neonatal thrombosis in our study was related to maternal infections during pregnancy with poor evaluation and management and high various manipulation that were done in NICUs that could lead to neonatal infections as central line insertion respiratory support with CPAP and respiratory support with endotracheal intubation. Cultures from health care providers, NICU environment and delivery room environment were needed to detect the prevalent microorganisms and source of infections.

\section{CONCLUSION}

The most important risk factor for thromboembolic events in neonates is placement of central catheters and some perinatal prothrombotic conditions. Nevertheless, hereditary or acquired thrombophilic risk factors may also be a cause of thrombo-embolism. We recommend that testing for genetic thrombophilia must be currently part of clinical routine in neonatal risk assessment of thrombosis, although some genetic risk factors are well established.

\section{REFERENCES}

1. Swoboda V, Zervan K, Thom K et al. (2017): Homozygous antithrombin deficiency type II causing neonatal thrombosis. Thrombosis Research, 158: 134-137.

2. Witmer C, Takemoto C (2017): Pediatric hospital acquired venous thromboembolism. Frontiers in Pediatrics, 5: 198-202.

3. Bacciedoni V, Attie M, Donato $\mathrm{H}$ et al. (2016): Thrombosis in newborn infants. Arch Argent Pediatr., 114 (2): 159-166.

4. Kenet G, Cohen O, Bajorat T et al. (2019): Insights into neonatal thrombosis. Thrombosis Research, 181: 33-36.
5. van Ommen C, Nowak-Göttl U (2017): Inherited thrombophilia in pediatric venous thromboembolic disease: why and who to test. Frontiers in Pediatrics, 5: 50-56.

6. Amankwah E, Atchison C, Arlikar S et al. (2014): Risk factors for hospital-associated venous thromboembolism in the neonatal intensive care unit. Thrombosis Research, 134 (2): 305-309.

7. Rakholia R, Rawat V, Bano M et al. (2014): Neonatal morbidity and mortality of sick newborns admitted in a teaching hospital of Uttarakhand. Chrismed J Health Res., 1 (4): $228-232$.

8. Verma J, Anand S, Kapoor N et al. (2018): Neonatal outcome in newborns admitted in NICU of tertiary care hospital in central India: a 5-year study. IJCP., 5 (4): 1364-7.

9. Ferraresi M, Arrais A (2016): Epidemiological profile of newborns' mothers admitted to a public neonatal unit. Revista da Rede de Enfermagem do Nordeste -Rev Rene, 17 (6): 73340.

10. El-Ganainy H, El-Mashad A, Shihab $\mathrm{N}$ et al. (2019): Risk Factors for Neonatal Mortality in Neonatal Intensive Care Units in Tanta City. EJHM., 75 (1): 1996-2006.

11. Farah A, Abbas A, Ahmed A et al. (2018): Trends of admission and predictors of neonatal mortality: A hospital based retrospective cohort study in Somali region of Ethiopia. PloS One, 13 (9): 203314.

12. Virupakshappa $P$, Rajendra $N$ (2018): Burden and spectrum of neonatal surgical diseases in a tertiary hospital: a decade experience. IJCP., 5 (3): 798-804.

13. Ugwu R, Okoro $P$ (2013): Pattern, outcome and challenges of neonatal thrombophilia in a tertiary teaching hospital. Afr $\mathbf{J}$ Paediatr Surg., 10 (3): 226-228.

14. Medhat $\mathbf{H}$, Khashana A (2017): Incidence of Neonatal Infection in South Sinai, Egypt. Int J Infect., 4 (1): 3661536619.

15. Getabelew A, Aman M, Fantaye E et al. (2018): Prevalence of neonatal sepsis and associated factors among neonates in neonatal intensive care unit at selected governmental hospitals in Shashemene Town, Oromia Regional State, Ethiopia, 2017. International Journal of Pediatrics, 1: 1-7.

16. Cailes B, Kortsalioudaki C, Buttery J et al. (2018): Epidemiology of UK neonatal infections: the neonIN infection surveillance network. ADC Fetal \& Neonatal, 103 (6): 547-53.

17. Heller C, Schobess R, Kurnik K et al. (2010): Abdominal Venous thrombosis in neonates and infants: Role of prothrombotic risk factors: A multicentre case-control study. For the Childhood Thrombophilia Study Group. Br J Haematol., 111: 534-539.

18. Martin-Ancel A, Garcia-Alix A, Gaya F et al. (2015): Multiple organ involvement in perinatal asphyxia. J Pediatr., 127: 786-793.

19. Martinelli I, Sacchi E, Landi G et al. (2018): High risk of cerebral vein thrombosis in carriers of a prothrombin-gene mutation and in users of oral contraceptives. New England Journal of Medicine, 338: 1793-1797.

20. Rosendaal F, Diggen C, Zivelin A et al. (2019): Geographic distribution of the $20210 \mathrm{G}$ to A prothrombin variant. Thrombosis and Haemostasis, 79: 706708.

21. Abdel-Wahab F, Ghoneim M, Khashaba M et al. (2013): Nosocomial infection surveillance in an Egyptian neonatal intensive care unit. J Hosp Infect., 83 (3): 196-9.

22. Gadallah M, Fotouh A, Habil I et al. (2014): Thrombophilia in a tertiary hospital neonatal intensive care unit in Egypt: 1year follow-up. Am J Infect Control, 42 (11): 1207-11. 